\title{
Direct steam injection pretreatment improves microwave-assisted extraction yield for total flavonoids and myricetin from Hovenia dulcis Thunb.
}

\author{
Yu-ling QU ${ }^{1 *}$, Dao-tao XIE ${ }^{2 *}$, Ching-yuan $\mathrm{HU}^{1}{ }^{\mathbb{B}}$, Hong $\mathrm{DENG}^{1 *}$, Yong-hong MENG ${ }^{1 *}$
}

\begin{abstract}
A direct steam injection pretreatment was added before the microwave-assisted extraction procedure for the extraction of flavonoids from seeds of Hovenia dulcis Thunb, and the antioxidant activity of flavonoid extracts was determined. Based on the experimental results, the addition of direct steam injection simultaneously increased the extraction yield of total flavonoids compared with direct microwave-assisted extraction, and antioxidant activity of flavonoid extracts obtained by adopting the steam injection pretreatment was higher than that by direct microwave extraction alone. Myricetin was isolated from the flavonoid extracts, and the structure was identified by infrared spectroscopy (IR), electrospray ionization mass spectrometry (ESI-MS), and $1 \mathrm{H}$ nuclear magnetic resonance (1H-NMR). Recovery yield of total flavonoids was increased by $11.63 \%$ when the direct steam injection pretreatment was added to direct microwave extraction.
\end{abstract}

Keywords: H. dulcis; DSI-MAE; response surface methodology; antioxidant activity; scanning electron microscopy.

Practical Application: Steam injection pretreatment presents distinctive advantages in superior extraction yield, higher antioxidant capacities of marker compound, and consequently shows excellent potential to be an alternative technique for flavonoids extraction from plants.

\section{Introduction}

Myricetin is a popular health food supplement commonly found in tea, berries, fruits, vegetables and medicinal herbs (Ross \& Kasum, 2002). Previous studies have shown that myricetin has immune-boosting, anti-oxidation, anti-tumor, anti-obesity and anti-inflammatory properties (Ross \& Kasum, 2002; Meng et al., 2016; Chhikara et al., 2018). Currently, the only source for the myricetin is isolated from the leaves of Myrica rubra, which is not sufficient to meet the expanding market demand. Finding an alternative source for myricetin production becomes a challenge to meeting this expanding demand.

Myricetin is the major flavonoid of the traditional herb, Hovenia dulcis Thunb. (H. dulcis). H.dulcis is a member of the genus Hovenia Thunb, primarily distributed in China, Korea, Japan, and India. H. dulcis has been widely cultivated in East Asia with a long history as food supplements and traditional medicine with high economic value (Hyun et al., 2010). Many food products are developed using H.dulcis such as beverages, crispy candy, fruit cakes, biscuits, and tea bags, while the seeds are disposed of as waste during food processing (Wang et al., 2018). Phytochemical investigations of $H$. dulcis have reported that the seeds have over ten kinds of flavonoids identified to date including myricetin as the major flavonoid (Xu et al., 2013). Therefore, $H$. dulcis seeds appeared to be a suitable source of myricetin to increase its production. However, the extraction method for the seeds needs development as no research on extraction methods has been reported.

Microwave-assisted extraction (MAE) is an important technique for extracting valuable compounds from plant materials (Albuquerque et al., 2018; Leão et al., 2018; Xu et al., 2018; Gómez et al., 2019). The microwave is an electromagnetic wave which can penetrate the plant matrix and cause heating in the cell to accelerate cell rupture to enhance the dissolution of compounds into the solvent. Generally, MAE has obvious benefits including a higher extraction yield, shorter extraction time, higher selectivity, and better quality of target extracts compared with conventional extraction methods (Tanongkankit et al., 2013). From the economic aspect, MAE is feasible as it requires a moderate cost of equipment and is much cheaper as compared to supercritical fluid extraction (SFE) (Chan et al., 2011). However, there are some drawbacks and limitations associated with MAE. For example, using a non-polar solvent as extraction solution should generally be discouraged because they are poor absorbents for microwave heating. However, in some cases, applications of non-polar solvent in MAE cannot be avoided because of their higher solubility for target compound compared to polar solvents. The contradicting facts have generated some difficulties in selecting solvents for MAE.

Many polarity-associated problems can be overcome by adding modifiers into nonpolar solvents to enhance the 
microwave absorbing capacity of the solvent (Elkhori et al., 2007; Mandal \& Mandal, 2010). In this study, direct steam injection (DSI), in which samples are treated under the high-pressure steam condition in a short time, was selected as an ancillary method for the extraction of total flavonoids from $H$. dulcis. DSI makes the sample cell wall corrupt through instant heating and enhances the efficiency of microwave heating by improving the raw material's water content. DSI exhibits high heat conduction rate and low time-spending, which shows potential advantages for extracting heat sensitive compounds, especially in combination with MAE as an auxiliary pretreatment method (Lewis \& Heppel, 2001; Lee et al., 2019). There has been no report on MAE by preprocessing with DSI, nor on the optimization of MAE parameters.

Therefore, the primary aim of our study was to illustrate the effect of DSI pretreatment method on MAE (DSI-MAE). Moreover, the MAE conditions including direct steam injection time, methanol extraction concentration, the ratio of solvent to a material, and extraction temperature for improving flavonoids extraction yield from $H$. dulcis were optimized. Finally, scanning electron microscopy was performed to further investigate the extraction mechanism of DSI-MAE in comparison with direct MAE. Thus, we have successfully developed an efficient extraction method to isolate and purify myricetin from $H$. dulcis flavonoids.

\section{Materials and methods}

\subsection{Materials and reagents}

The $H$. dulcis seeds were harvested from the Xunyang region of Shaanxi Province of China. The myricetin standard was obtained from the National Institute for the Control of Pharmaceutical and Biological Products (Beijing, China). MAE was carried out using a microwave (NJC 03-2, $2450 \mathrm{MHz}$, out-put $0.2-0.6 \mathrm{kw}$, extract volume $3 \mathrm{~L}$; Nanjing Jiequan, China), it can hold a stable temperature by the jacket water. Silica gel and D101 macroporous resin was purchased from the Chemical Plant of Nankai University (Tianjin, China). 1, 1-Diphenyl-2-picrylhydrazyl (DPPH), 2, 2'-azino-bis (3-ethylbenzothiazoline-6-sulfonic acid) diammonium salt (ABTS), and rutin (purity $>98 \%$ ) were obtained from Sigma-Aldrich $\mathrm{GmbH}$ (Steinheim, Germany). All other reagents used in this investigation were of analytical grade.

\subsection{Pretreatment procedure}

The air-dried $H$. dulcis seeds were milled into powder by a grinder and screened through an 80-mesh sieve. DSI pretreatment was conducted in a small bath unit equipped with $2 \mathrm{~L}$ reaction vessel. A water impregnation of the raw material before DSI pretreatment was carried out by soaking $100 \mathrm{~g}$ of powder in $1.5 \mathrm{~L}$ of water overnight, then the excess liquid removed by filtration. The pressure reactor was preheated to $121^{\circ} \mathrm{C}$ by saturated steam. After added the raw material into the reactor, the injection was about $60 \mathrm{~s}$ with the direct steam to reach $121^{\circ} \mathrm{C}$. The parameters of direct steam injection were fixed during the experiment. Briefly, the powder was injected by direct steam at different times.

\subsection{Extraction method}

\section{Microwave-assisted extraction}

The residue was extracted using microwave irradiation at the set temperatures for $30 \mathrm{~min}$. During extraction, the powdersolvent mixture was stirred at regular intervals. After extraction, the mixture was cooled to room temperature and centrifuged at $3250 \times g$ for $10 \mathrm{~min}$. The supernatants were filtered through microporous membranes $(0.45 \mu \mathrm{m})$, and the filtrates were collected as flavonoid extracts. The flavonoid extracts were reduced to a small volume by vacuum rotary evaporation at $45-55^{\circ} \mathrm{C}$ and freeze-dried.

\section{Optimization of the microwave-assisted extraction conditions}

The single-factor experiment method was used to study the influence to of three factors of microwave-assisted extraction: methanol solution (methanol concentration: $40 \%-80 \%$, v/v), solid content (solvent to the material ratio: $20-60 \mathrm{ml} / \mathrm{mg}$ ), and temperature $\left(30-70^{\circ} \mathrm{C}\right)$ on the extraction efficiency of total flavonoids,

Response surface method (RSM) with a Box-Behnken design was used to optimize the three optimal parameters of each factor further. Coding limits and levels of these factors are indicated in Table 1. Experiments consist of 17 tests. Test design is performed as a function of the main parameters. System dynamics can be explained using quadratic equation (Gasemloo et al., 2019) (Equation 1).

$$
y=\beta_{0}+\sum_{i=1}^{k} \beta_{i} x_{i}+\sum_{i=1}^{k} \beta_{i i} x_{i}^{2}+\sum_{i=1}^{k} \sum_{j=l}^{k} \beta_{i j} x_{i} x_{j}+\varepsilon
$$

where, $y$ represents the predicted response for the elimination efficiency, $\beta$ o is a constant factor, $\beta_{\mathrm{i}}$ is coefficient of linear effects, $\beta_{\mathrm{ii}}$ is coefficient square effects, $\beta_{\mathrm{ij}}$ is factor interactions, while $\mathrm{x}_{\mathrm{i}}$ and $\mathrm{x}_{\mathrm{j}}$ are variables and $\varepsilon$ is the random error.

\section{Determination of total flavonoids}

An aliquot $(2 \mathrm{~mL})$ of the sample was mixed with $0.2 \mathrm{~mL}$ of $5 \%$ sodium nitrite. After $5 \mathrm{~min}, 0.2 \mathrm{~mL}$ of $10 \%$ aluminum chloride was added to the mixture and mixed. Two $\mathrm{mL}$ of $1 \mathrm{~mol} \mathrm{~L}^{-1}$ sodium hydroxide was added to the mixture after $6 \mathrm{~min}$. The end volume of the reaction mixture was brought up to $5 \mathrm{~mL}$ with aqueous methanol and mixed thoroughly. Absorbance was measured at $412 \mathrm{~nm}$ versus a $75 \%$ methanol blank. Rutin was used to make the calibration curve, and the flavonoid content was expressed as milligram rutin equivalents (RE) $\mathrm{g}^{-1}$ dried plant powder. Samples were analyzed in triplicate.

Table 1. Levels of the independent test variables.

\begin{tabular}{lccc}
\hline \multirow{2}{*}{ Factors } & \multicolumn{3}{c}{ levels } \\
\cline { 2 - 4 } & -1 & 0 & +1 \\
\hline A: Methanol extraction concentration $(\%)$ & 50 & 60 & 70 \\
B: Ratio of solvent to material $\left(\mathrm{mL} \mathrm{g}^{-1}\right)$ & $40: 1$ & $50: 1$ & $60: 1$ \\
C: Extraction temperature $\left({ }^{\circ} \mathrm{C}\right)$ & 50 & 60 & 70 \\
\hline
\end{tabular}




\subsection{Antioxidant activity assay}

\section{Radical-scavenging activity toward DPPH•}

$0.04 \mathrm{mg} \mathrm{mL}^{-1} \mathrm{DPPH} \bullet$ in methanol solution was prepared, and $2.0 \mathrm{~mL}$ of this solution was added to $1.0 \mathrm{~mL}$ of flavonoid extracts at various concentrations $\left(0.05-2.00 \mathrm{mg} \mathrm{mL}^{-1}\right)$. The resulting mixture was shaken vigorously and incubated at $28^{\circ} \mathrm{C}$ for $30 \mathrm{~min}$ in the dark. The mixture's absorbance was measured at $517 \mathrm{~nm}$ after incubation using an ultraviolet-visible spectrophotometer. The scavenging activity was calculated by the following equation:

Scavenging activity $(\%)=\left(1-A_{m} / A_{0}\right) \times 100 \%$

Where Am is the absorbance of the samples (the mixture of flavonoid extracts, methanol, and DPPH• solution), $A_{0}$ is the absorbance of the blank control (the mixture of methanol and $\mathrm{DPPH} \bullet$ solution).

\section{Radical-scavenging activity toward $\mathrm{ABTS}^{+}$•}

Determination of the $\mathrm{ABTS}^{+} \bullet$ radical-scavenging activity was based on the method by Siler et al. (Siler et al., 2014) with minor modifications. $\mathrm{ABTS}^{+} \bullet$ was generated by oxidation of $7.40 \mathrm{mmol}$ $\mathrm{L}^{-1}$ ABTS with $2.60 \mathrm{mmol} \mathrm{L}^{-1}$ potassium persulfate solution in the dark at room temperature for $12-16 \mathrm{~h}$. After the reaction, the $\mathrm{ABTS}^{+} \bullet$ solution was diluted with methanol to an absorbance of $0.700 \pm 0.020$ at $734 \mathrm{~nm}$. The mixture was prepared by mixing 0.8 $\mathrm{mL}$ of the $\mathrm{ABTS}^{+}$. solution, and $2.0 \mathrm{~mL}$ of the flavonoid extract concentrations from 0.05 to $2.00 \mathrm{mg} \mathrm{mL}^{-1}$. The reaction mixture was incubated for $6 \mathrm{~min}$ at room temperature, and the absorbance at $734 \mathrm{~nm}$ was measured. The $\mathrm{ABTS}^{+} \bullet$ radical scavenging activity (\%) was calculated using the following formula:

Scavenging activity $(\%)=\left(1-A_{m} / A_{0}\right) \times 100 \%$

Where $A_{\mathrm{m}}$ is the absorbance of the samples (the mixture of flavonoid extracts, methanol, and $\mathrm{ABTS}^{+} \bullet$ solution), $A_{0}$ is the absorbance of the blank control (the mixture of methanol and $\mathrm{ABTS}^{+} \bullet$ solution).

\subsection{Isolation of myricetin from flavonoid extracts}

The combined extracts were filtered and concentrated under vacuum. Twenty milliliters of concentrated solution was loaded onto a D101 macroporous resin column $(5.0$ i.d. $\times 100 \mathrm{~cm})$, followed by elution with distilled water, $6 \%$ aqueous methanol, and $60 \%$ aqueous methanol. The $60 \%$ aqueous methanol eluent was collected and concentrated. The extract was loaded onto a silica gel column and then eluted with petroleum-ethylacetate-acetic acid (5:1:0.1) and petroleum-ethylacetate-acetic acid (1:1:0.1) to obtain the desired compound. The final eluate was concentrated and dried once again. The dried sample was repeatedly recrystallized with five times $(\mathrm{m} / \mathrm{v})$ methanol to obtain highly purified myricetin.

\subsection{Structural identification of myricetin}

The identification of myricetin was performed by the infrared spectroscopy (IR) spectra recorded on a Fourier transform Infrared Spectrometer (EQUINX55; Bruker Corporation, Germany). The electrospray ionization mass spectrometry (ESI-MS) spectra were measured on a Bruker Apex III FT ion cyclotron resonance mass spectrometer in the positive ionization mode at a potential of $4.0 \mathrm{kV}$ (on the discharge needle). The ${ }^{1} \mathrm{H}$ nuclear magnetic resonance $\left({ }^{1} \mathrm{H}-\mathrm{NMR}\right)$ spectra were recorded on a Bruker AMX 400 spectrometer from Bruker Biospin (Rheinstetten, Germany) operating at a proton frequency of $400 \mathrm{MHz}$.

\subsection{Scanning electron microscopy}

After removing the solvent, samples were dried and plunged in liquid nitrogen for freezing treatment. A cold knife was used for cutting frozen samples to particles which were then fixed on a specimen holder and sputtered with gold in an ion sputtering instrument (SCD005, Baltek, U.S.A.). The processed samples were examined by a scanning electron microscopy (Tecnai G2 F20, FEI, U.S.A.) at an accelerating voltage of $20.0 \mathrm{kV}(20 \mu \mathrm{m}$, $5000 \times$ magnification).

\subsection{Statistical analysis}

Each experiment was repeated three times. The data presented are the mean \pm standard deviation (SD). Analysis of variance and regression coefficient values calculation for RSM model were performed using Design Expert 8.0 statistical software. $P<0.05$ was considered statistical significance.

\section{Results and discussion}

\subsection{Effect of direct steam injection pretreatment on flavonoids extraction}

The effects of steam injection time on flavonoids extraction were studied by using fixed conditions of direct steam injection and specific microwave conditions: the methanol extraction concentration is $40 \%$, the extraction temperature is $30{ }^{\circ} \mathrm{C}$, the ratio of solvent to the material is $20 \mathrm{~mL} / \mathrm{mg}$. As shown in Figure 1a, compared with $10 \mathrm{~min}$, the extraction of flavonoids (w/w) increased significantly after 20 to 50 minutes by steam injection, in which extraction increase from 0 to $20 \mathrm{~min}$, and decrease gradually after maximum extraction of $20 \mathrm{~min}$. The steam injection treatment results in the violent vaporization of the polar liquor (e.g., water) inside plant tissues and cells and the pressure may rupture (or even penetrate) the cell walls and tissue surfaces. Thus, destruction of $H$. dulcis cells and tissues resulting from microwave irradiation most probably facilitates mass transfer between flavonoids and the surrounding extractant and subsequently improves the extraction efficiency. The extraction decreases after $20 \mathrm{~min}$, which shows that the solubility of flavonoids is affected by the increase in water content. As flavonoids have better solubility in methanol other than water, the increasing of water content results in lower solubility in extractant thus reduces the extraction efficiency of flavonoids.

\subsection{Effects of operation parameters of microwave-assisted extraction on the yield}

A broad range of factors may influence the MAE of secondary metabolites from plants. The effects of methanol concentration, 

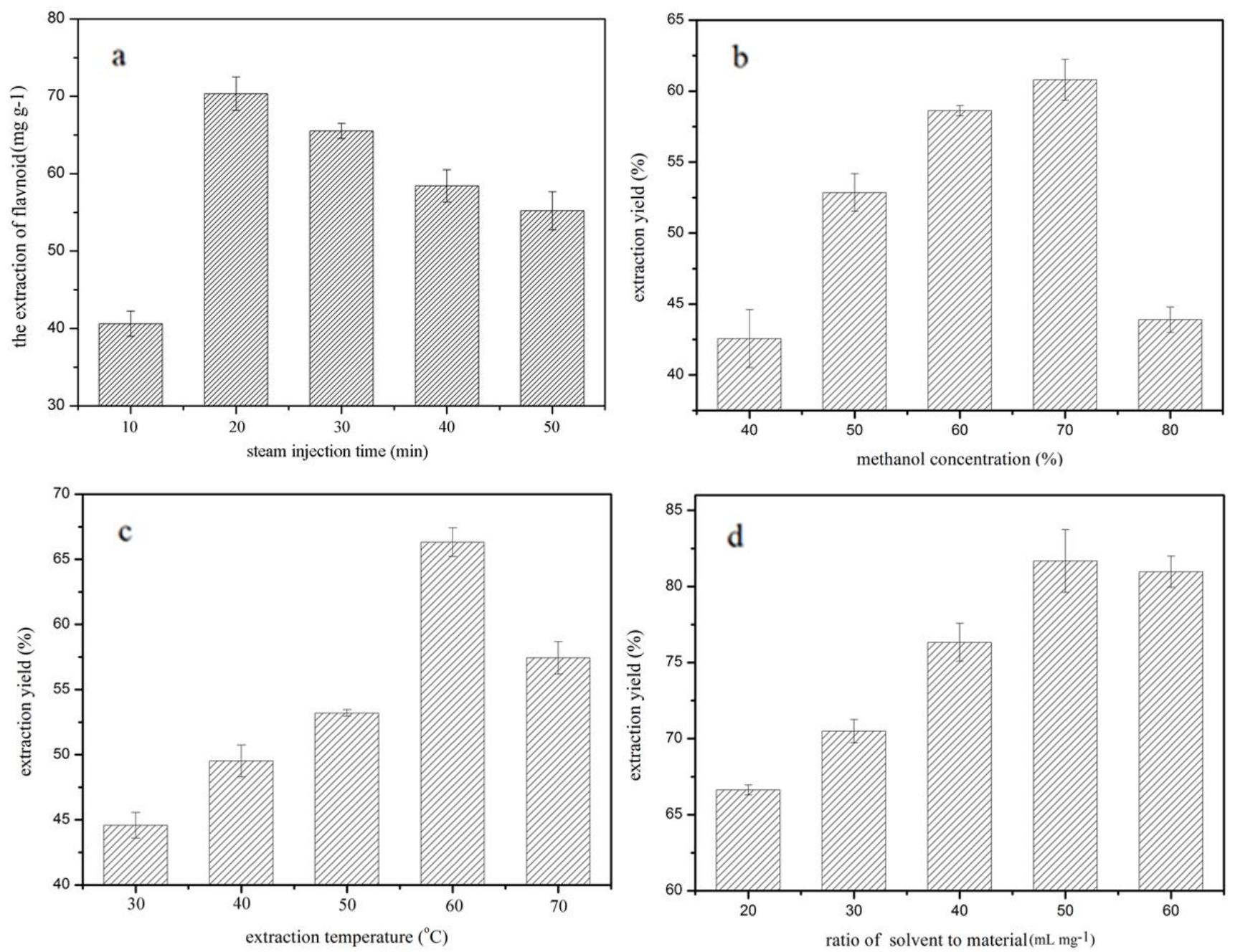

Figure 1. Effect of steam injection times on pretreatment, microwave-assisted extraction conditions: the methanol extraction concentration is $40 \%$, the extraction temperature is $30^{\circ} \mathrm{C}$, the ratio of solvent to the material is $20 \mathrm{~mL} / \mathrm{mg}$ (a). Effect of methanol extraction concentration on the extraction yield of total flavonoids, the steam injection time is $20 \mathrm{~min}$, microwave-assisted extraction conditions: the extraction temperature is $30{ }^{\circ} \mathrm{C}$, and the ratio of solvent to the material is $20 \mathrm{~mL} / \mathrm{mg}$ (b). Effect of extraction temperature on the extraction yield of total flavonoids, the steam spray injection is $20 \mathrm{~min}$, microwave-assisted extraction conditions: the methanol extraction concentration is $70 \%$, and the ratio of solvent to the material is 20:1 (c), Effect of the ratio of solvent to solvent on the extraction yield of total flavonoids, the steam injection time is 20 min, microwave-assisted extraction conditions: the methanol extraction concentration is $70 \%$, and the extraction temperature is $60{ }^{\circ} \mathrm{C}(\mathrm{d})(\mathrm{n}=3)$.

extraction temperature and the solvent ratio to the material on the extraction yield of flavonoid were studied successively under fixed direct steam injection for $20 \mathrm{~min}$. The influence of methanol concentration was studied under the conditions of the extraction temperature at $30{ }^{\circ} \mathrm{C}$. The solvent ratio to the material of $20 \mathrm{~mL} / \mathrm{mg}$, the influence of the extraction temperature was studied under the optimal methanol concentration. The solvent ratio to the material of $20 \mathrm{~mL} / \mathrm{mg}$, and the influence of the solvent ratio to the material was studied under the optimal methanol concentration and extraction temperature. The results of single-factor experiments are presented in Figure 1.

In general, the solvent was considered an essential factor for MAE because it might affect the absorption of microwave energy and the solubility of the target ingredients (Hemwimon et al., 2007). The impact of methanol concentration on the extraction yield of total flavonoids is shown in Figure 1b. Remarkably, both the $40 \%$ methanol solution and $80 \%$ methanol solution led to a comparatively low extraction yield. When the methanol extraction concentration increased to $70 \%(\mathrm{v} / \mathrm{v})$, the extraction yield improved dramatically. However, the extraction yield decreased at higher methanol extraction concentrations $(>70 \%)$. One possible reason is that the affinity of the $70 \%$ methanol solution for the flavonoids is higher than that of the $40 \%$ methanol solution and the $80 \%$ methanol solution. Another possible explanation is that the aqueous methanol solution facilitates the swelling of seed powders, which increases the surface area for solvent-sample contact (Xiao et al., 2008).

Increasing temperature is the result of microwave energy delivery, and the use of higher power increases the extraction temperature. As shown in Figure 1c, the extraction yield of the 
flavonoids increased with the increase of extraction temperature from 30 to $60^{\circ} \mathrm{C}$. However, the extraction yield decreased from 60 to $70{ }^{\circ} \mathrm{C}$. One explanation for the decrease in yield is that the methanol was evaporated when the temperature was higher than the boiling point of methanol $\left(64^{\circ} \mathrm{C}\right)$, and the solution polarity changed resulting in the reduction of the extraction yield.

Figure 1d illustrates the effects of the ratio of solvent to material on the extraction yield of total flavonoids. The result indicated that the extraction yield of total flavonoids drastically increased as the ratio of solvent to material increased from 20:1 to 50:1. Nevertheless, the extraction yield showed a slight downward tendency when the ratio was beyond 50:1. Taking into account the cost savings of solvent and material, the ratio of solvent to the material should not exceed 50:1.

We adopted a methanol extraction concentration of $50-70 \%$, a ratio of solvent to the material of 40:1-60:1, and an extraction temperature of $50-70^{\circ} \mathrm{C}$ for the RSM experiments based on the results of the single-factor experiments.

\subsection{Optimization of the extraction parameters of flavonoids}

\section{Statistical analysis and the model fitting}

According to the parameter obtained in the single-factor experiment and the method of the Box-Behnken designed experiment, and the RSM was applied to determine the optimum conditions of extraction. We analyzed the data by multiple regression analysis using Design-Expert 8.0. Table 2 shows the process variables and experimental data. The percentage yield ranged from $71.19 \%$ to $79.71 \%$. The maximum yield of total flavonoids $(79.71 \%)$ was recorded at a methanol extraction concentration of $70 \%$, the ratio of solvent to the material of 46:1, and extraction temperature $64^{\circ} \mathrm{C}$. The application of RSM suggested was based on the parameter estimates, and an empirical formula between the response variable (extraction yield of total flavonoids) and the test variable was determined as shown below (Equation 4).

$Y(\%)=-50.31875-0.022650 \times A+3.30787 \times B-0.034295 \times B^{2}-0.011295 \times C^{2}$

The results of the analysis of variance, goodness-of-fit, and the adequacy of the models are summarized in Table 3. The $F$-test, $P$-value, and lack of fit were used to measure the significance of the coefficient of the model. The F-value of 32.55, a low probability $P$-value $(P<0.0001)$ with a lack of fit of 0.1446 indicates the model is adequate for predicting the yield within the range of the variables employed. The value of the coefficient determination $\left(\mathrm{R}^{2}=0.9767\right)$ also confirmed that the model was highly reliable. Besides, a very low value of $0.84 \%$ for the coefficient of the variation (CV) demonstrated a high degree of precision and excellent reliability for the experimental values.

The model is adequate for prediction within the range of experimental variables. The regression coefficient values of Eq. (4) are listed in Table 3. The $P$-values were used to check the significance of each coefficient, which in turn might indicate the pattern of the interaction between the variables. The smaller the value of $P$ was, the more significant the corresponding
Table 2. Box-Behnken experimental design with three independent variables.

\begin{tabular}{|c|c|c|c|c|}
\hline \multirow{3}{*}{$\begin{array}{c}\text { Run } \\
\text { number }\end{array}$} & \multicolumn{3}{|c|}{ Variable level } & \multirow{3}{*}{$\begin{array}{l}\text { Extraction } \\
\text { yield of total } \\
\text { flavonoids } \\
(\%)\end{array}$} \\
\hline & $\begin{array}{c}\text { Methanol } \\
\text { extraction } \\
\text { concentration } \\
(\%)\end{array}$ & $\begin{array}{c}\text { Ratio of } \\
\text { solvent to } \\
\text { material } \\
(\mathrm{mL} \text { g- } 1)\end{array}$ & $\begin{array}{l}\text { Extraction } \\
\text { temperature } \\
\left({ }^{\circ} \mathrm{C}\right)\end{array}$ & \\
\hline & A & B & $\mathrm{C}$ & \\
\hline 1 & 50 & $60: 1$ & 60 & $71.40 \pm 0.64$ \\
\hline 2 & 60 & $60: 1$ & 50 & $72.36 \pm 0.55$ \\
\hline 3 & 50 & $50: 1$ & 50 & $75.90 \pm 0.17$ \\
\hline 4 & 60 & $50: 1$ & 60 & $78.10 \pm 0.73$ \\
\hline 5 & 60 & $40: 1$ & 50 & $75.96 \pm 0.24$ \\
\hline 6 & 60 & $50: 1$ & 60 & $79.08 \pm 0.59$ \\
\hline 7 & 60 & $50: 1$ & 60 & $78.46 \pm 0.21$ \\
\hline 8 & 60 & $50: 1$ & 60 & $79.10 \pm 0.38$ \\
\hline 9 & 70 & $40: 1$ & 60 & $78.08 \pm 0.34$ \\
\hline 10 & 70 & $50: 1$ & 70 & $79.25 \pm 0.57$ \\
\hline 11 & 50 & $50: 1$ & 70 & $77.46 \pm 0.65$ \\
\hline 12 & 60 & $40: 1$ & 70 & $77.31 \pm 0.78$ \\
\hline 13 & 50 & $40: 1$ & 60 & $77.89 \pm 0.25$ \\
\hline 14 & 70 & $60: 1$ & 60 & $73.16 \pm 0.60$ \\
\hline 15 & 60 & $50: 1$ & 60 & $79.08 \pm 0.27$ \\
\hline 16 & 60 & $60: 1$ & 70 & $71.19 \pm 0.18$ \\
\hline 17 & 70 & $50: 1$ & 50 & $77.12 \pm 0.83$ \\
\hline
\end{tabular}

Table 3. Analysis of variance for the quadratic polynomial equation designed to assess total flavonoids yield.

\begin{tabular}{cccccr}
\hline Variables $^{\mathrm{a}}$ & \multicolumn{1}{c}{$\mathrm{SS}^{\mathrm{b}}$} & $\mathrm{DF}^{\mathrm{b}}$ & $\mathrm{MS}^{\mathrm{b}}$ & F-value & P-value \\
\hline Model & 120.69 & 9 & 13.41 & 32.55 & $<0.0001$ \\
$\mathrm{~A}$ & 3.08 & 1 & 3.08 & 7.47 & 0.0292 \\
$\mathrm{~B}$ & 55.81 & 1 & 55.81 & 135.49 & $<0.0001$ \\
$\mathrm{C}$ & 1.87 & 1 & 1.87 & 4.54 & 0.0705 \\
$\mathrm{AB}$ & 0.62 & 1 & 0.62 & 1.50 & 0.2609 \\
$\mathrm{AC}$ & 0.081 & 1 & 0.081 & 0.20 & 0.6704 \\
$\mathrm{BC}$ & 1.59 & 1 & 1.59 & 3.85 & 0.0904 \\
$\mathrm{~A} 2$ & 0.17 & 1 & 0.17 & 0.42 & 0.5390 \\
$\mathrm{~B} 2$ & 49.52 & 1 & 49.52 & 120.22 & $<0.0001$ \\
$\mathrm{C} 2$ & 5.37 & 1 & 5.37 & 13.04 & 0.0086 \\
Residual & 2.88 & 7 & 0.41 & & \\
Lack of fit & 2.04 & 3 & 0.68 & 3.21 & 0.1446 \\
Pure error & 0.85 & 4 & 0.21 & & \\
& $\mathrm{R}^{2}=$ & $\mathrm{CV}$ & & & \\
\hline
\end{tabular}

${ }^{\mathrm{a} A}$ : methanol extraction concentration; B: ratio of solvent to material; C: extraction temperature. ${ }^{\text {bSS: }}$ sum of squares; DF: degree of freedom; MS: mean square; CV: coefficient of the variation.' 
coefficient was. This table shows that the linear coefficients $(\mathrm{A}, \mathrm{B})$, and the quadratic term coefficients $\left(\mathrm{B}^{2}, \mathrm{C}^{2}\right)$ had small $P$-values $(P<0.05)$, whereas the linear coefficients $(C)$, the cross-product coefficients $(\mathrm{AB}, \mathrm{AC}, \mathrm{BC})$ and the quadratic term coefficients $\left(\mathrm{A}^{2}\right)$ had $P$-values over 0.05 on the extraction yield of total flavonoids. By analyzing the linear and quadratic coefficients, we concluded that the order of factors influencing the response value of the extraction yield of total flavonoids was as follows: the ratio of solvent to material $>$ methanol extraction concentration $>$ extraction temperature. The full model shown by Equation 4 was plotted in a 3-D format, and contour plots were used to predict the relationships between the independent variables and the dependent variables.

\section{Response surface analysis}

The 3-D response surfaces and two-dimensional contour plots are the graphical representations of the regression function. They are presented in Figure 2 for the independent variables (methanol extraction concentration, the ratio of solvent to the material, and extraction temperature) and were obtained by keeping two of the variable's constant, which indicated the changes in extraction yield under different conditions.

Each figure shows the effects of two factors on the total flavonoids yield while the other one was kept at the zero level. The 3-D plot and the contour plot in Figure 2a and d, which set the extraction temperature at the zero level, showed that the extraction yield of total flavonoids increased with increases in the methanol concentration from 50 to $70 \%$. The extraction yield of total flavonoids increased with increases in the ratio of solvent to material from 40 to $52 \mathrm{~mL} \mathrm{~g}^{-1}$, but beyond $52 \mathrm{~mL} \mathrm{~g}^{-1}$, the yield of total flavonoids increased slowly as the ratio of material to solvent further increased.

Figure $2 \mathrm{~b}$ and e showed the 3-D plot and the contour plot at varying methanol extraction concentrations and extraction temperatures at a fixed ratio of solvent to the material (zero level). From Figure $2 \mathrm{~b}$ and e, it can be seen that the extraction yield of total flavonoids increased with increases in the extraction temperature from 50 to $64^{\circ} \mathrm{C}$, but beyond $64^{\circ} \mathrm{C}$, the yield of total flavonoids decreased slowly as the extraction temperature further increased. From Figure $2 \mathrm{c}$ and $\mathrm{f}$, it is evident that the extraction yield of total flavonoids increased rapidly with the increasing ratio of solvent to material from 40 to $52 \mathrm{~mL} \mathrm{~g}^{-1}$, but beyond $50 \mathrm{~mL} \mathrm{~g}^{-1}$, the yield of total flavonoids decreased slowly as the ratio of solvent to material further increased. The yield of total flavonoids also increased rapidly when the extraction temperature was less than $64{ }^{\circ} \mathrm{C}$, and then decreased slowly after $64^{\circ} \mathrm{C}$.

\subsection{Validation of the model}

By using OriginLab 8.0 software, the optimum condition for total flavonoids extraction was identified as $70 \%$ methanol extraction concentration, 46.37:1 ratio of solvent to the material, and an extraction temperature of $63.78^{\circ} \mathrm{C}$. The estimated value for the extraction yield of $79.71 \%$ was obtained under these conditions.

To further test the reliability of the experimental method, the extraction experiment was carried out by adopting an optimal analytical model. Using an adjusted extraction condition of $70 \%$ methanol extraction concentration, $46: 1$ ratio of solvent to the material, and an extraction temperature of $64^{\circ} \mathrm{C}$, a mean value of $80.17 \pm 0.29(n=3)$ was obtained, demonstrating the validation of the RSM model. Consequently, the condition a
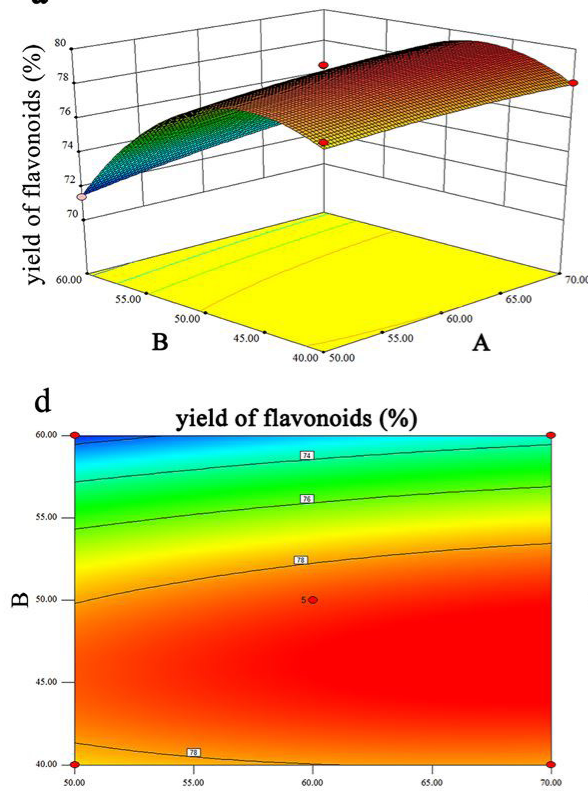

A b

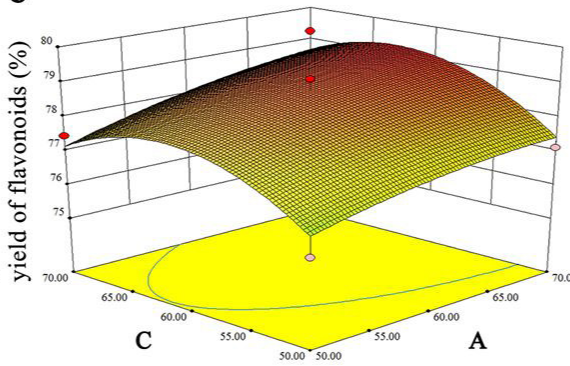

e

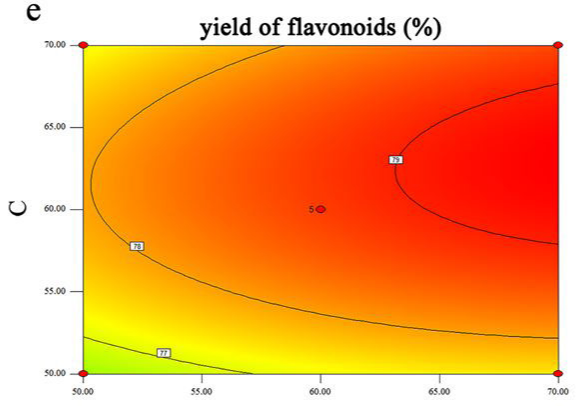

A

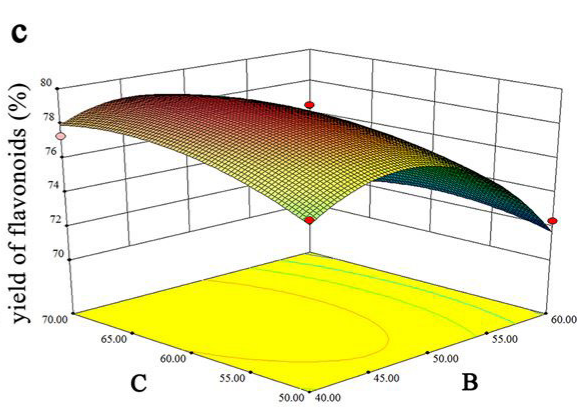

f

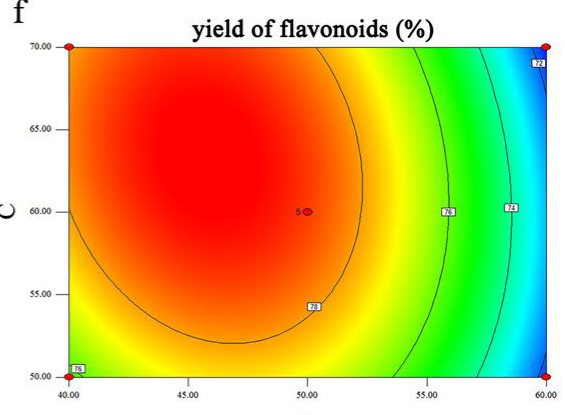

B

Figure 2. 3D Response surface ( $a, b$ \& c) and $2 D$ contour (d, e \& f) plots showing the effects of different parameters on the extraction yield of

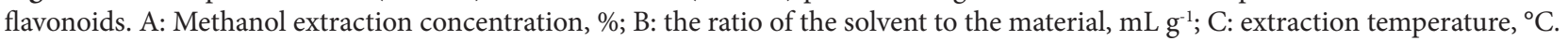


described above was proven to be the most optimal combination of the different parameters.

\subsection{Comparison of DSI-MAE with direct MAE on total flavonoids extraction}

The results of comparative studies on recovery yield of total flavonoids of total flavonoids obtained by DSI-MAE and direct MAE, respectively. Notably, the higher recovery yield (80.17\%) was achieved by DSI-MAE, followed by direct MAE (68.54\%), which is close to the optimal extraction yield calculated by RSM (79.71\%). This represents an $11.63 \%$ increase in recovery yield as a result of using the DSI procedure. Therefore, we have demonstrated that applying the DSI technique to the extraction of secondary metabolites from plants significantly improves extraction yield.

We used scanning electron microscopy to explore the mechanism of DSI-MAE on total flavonoids extraction further using samples from DSI-MAE and direct MAE, and the micrographs are shown in Figure 3 DSI-MAE micrographs
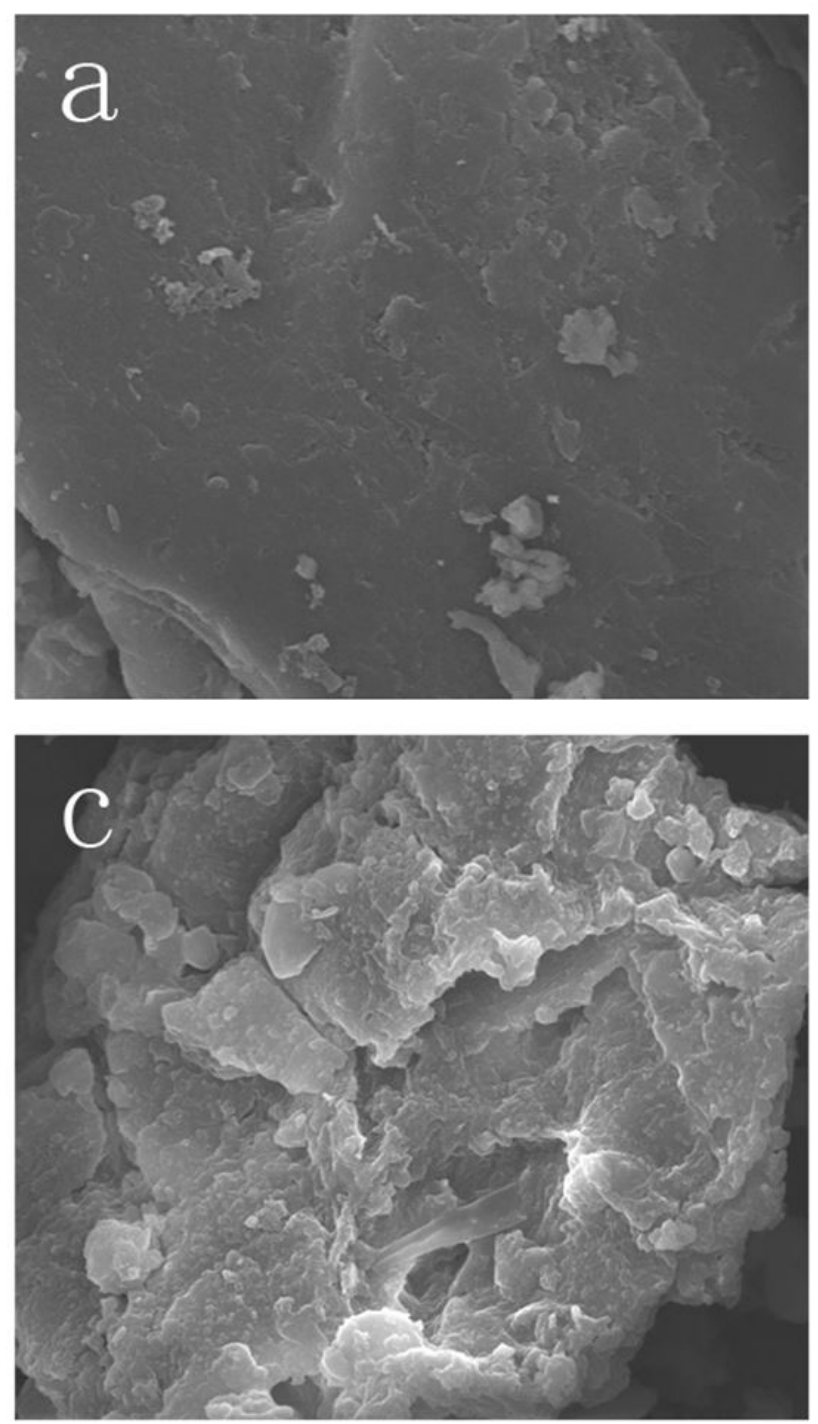

(c, d) shows obvious ruptures throughout the sample surface, while direct MAE micrographs $(a, b)$ exhibits relative flat surface with only a few ruptures. The surface of the DSI-MAE sample was extraordinarily destroyed due to instant heating by steam. Additionally, the water content enhancement in sample strengthened MAE efficiency in subsequent microwave heating. As sample surface was fractured, chemical substances seeped out from cells through ruptures and dissolved into solvents outside, which enhanced solvent extraction of components.

\subsection{Antioxidant activity assays of flavonoid extracts}

One important aspect of comparing MAE by different pretreatment methods is the quality (e.g., bioactivity) of the resultant extracts. Two common approaches, $\mathrm{DPPH} \bullet$, and $\mathrm{ABTS}^{+} \bullet$ assays were employed to assess relative antioxidant activities of flavonoid extracts by various pretreatment methods. To distinctively compare antioxidant capacities of flavonoid extracts between different pretreatment methods, the graph of $\mathrm{DPPH} \bullet$ and $\mathrm{ABTS}^{+} \bullet$ radical-scavenging activities was
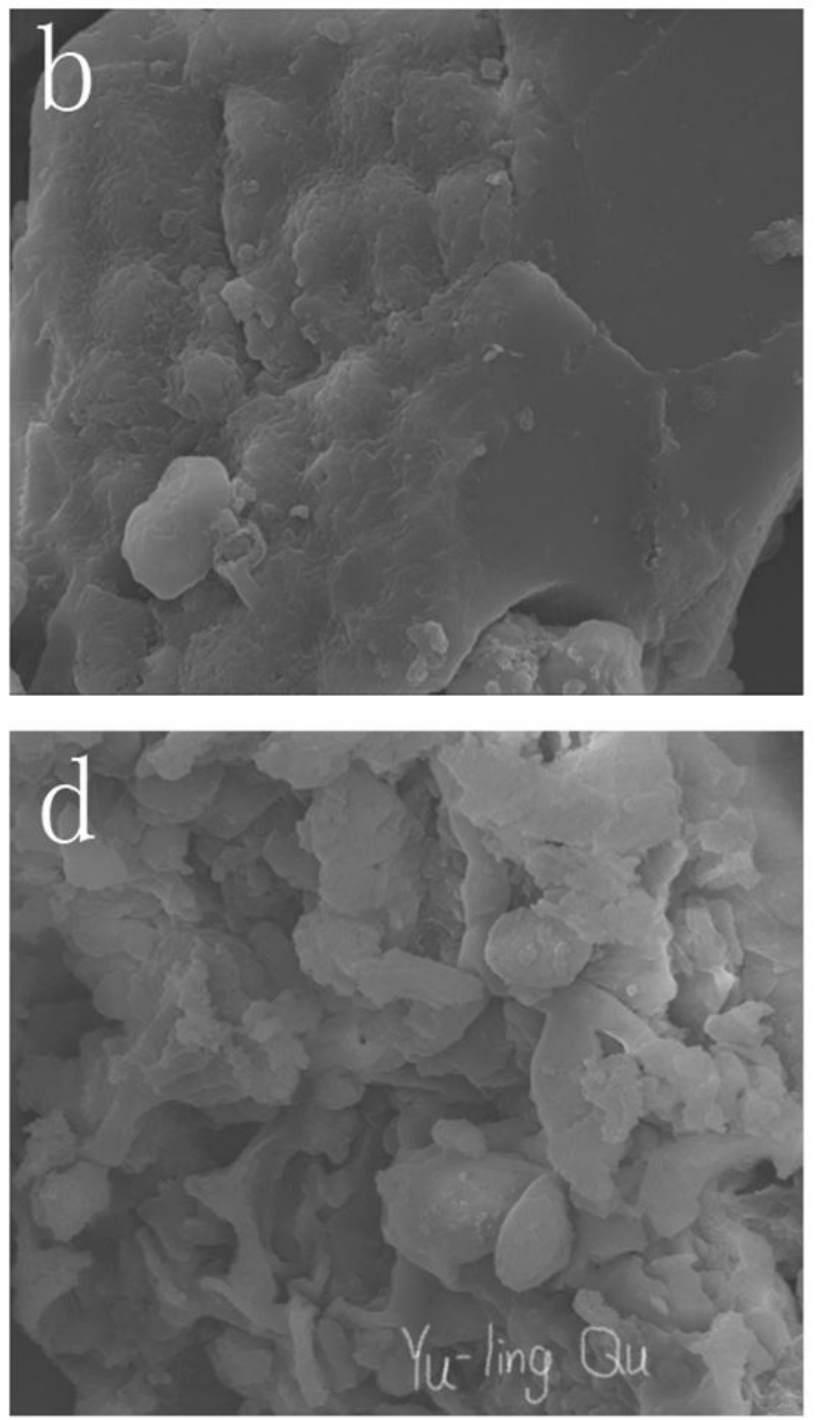

Figure 3. Scanning electron micrographs of plant samples: (a, b) direct MAE; (c, d) DSI-MAE. 
generated by increasing the concentration of flavonoid extracts and plotting radical-scavenging activities against it (Cao et al., 2013). DPPH• and $\mathrm{ABTS}^{+}$• radical-scavenging activities of flavonoid extracts were observed to be in a dose-dependent manner (Figure 4). By three-parameter logarithmic fitting to obtain equations between extracts concentration and activity, IC50 for each pretreatment method was acquired and shown in Table 4. A significant difference in antioxidant capacities was found between DSI-MAE and direct MAE $(P<0.05)$. The highest radical-scavenging activity was achieved by DSI-MAE with lower IC50 concentration $(0.35606 \mathrm{mg} / \mathrm{mL}$ for DPPH• and $0.41477 \mathrm{mg} / \mathrm{mL}$ for $\left.\mathrm{ABTS}^{+} \bullet\right)$ than direct $\mathrm{MAE}(0.86490$ $\mathrm{mg} / \mathrm{mL}$ for DPPH• and $1.49116 \mathrm{mg} / \mathrm{mL}$ for $\mathrm{ABTS}^{+} \bullet$ ). The results based on $\mathrm{DPPH} \bullet$ and $\mathrm{ABTS}^{+} \bullet$ assays revealed that DSI did not lower antioxidant activity of flavonoid extracts; on the contrary, with the assistance of steam injection, the scavenging ability of flavonoid extracts on $\mathrm{DPPH} \bullet$ and $\mathrm{ABTS}^{+} \bullet$ radicals increased. The relatively higher antioxidant activity, extracted by DSI preprocessing, suggests it may have more flavonoids and bioactivity ingredients in extracts.

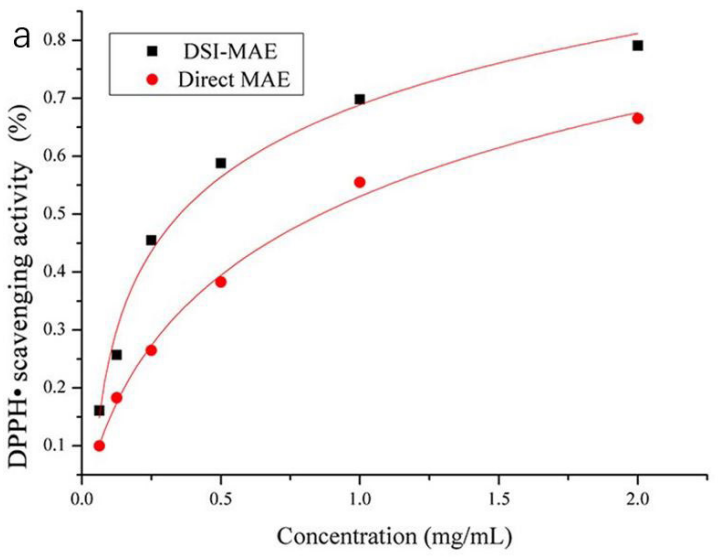

\subsection{Isolation and identification of myricetin from flavonoid extracts}

The IR spectra of myricetin indicate the presence of hydroxyl $\left(3422 \mathrm{~cm}^{-1}\right)$, carbonyl $\left(1663 \mathrm{~cm}^{-1}\right)$, and aromatic groups (160399, $\left.1514 \mathrm{~cm}^{-1}\right)$, the $[\mathrm{M}-\mathrm{H}]^{- \text {the }}$ peak of myricetin was observed at $\mathrm{m} / \mathrm{z} 317$, and its molecular formula was $\mathrm{C}_{15} \mathrm{H}_{10} \mathrm{O}_{8}$ (Figure 5). The ${ }^{1} \mathrm{H}$-NMR spectral (DMSO- $\mathrm{d}_{6}, 400 \mathrm{MHz}$ ) results were as follows:

Table 4. Logarithmic fitting equations and IC50 for antioxidant activities of DSI-MAE and direct MAE.

\begin{tabular}{cccc}
\hline $\begin{array}{c}\text { Extraction } \\
\text { Method }\end{array}$ & $\begin{array}{c}\text { Activity } \\
\text { Method }\end{array}$ & Equation & $\begin{array}{c}\mathrm{IC50} \\
(\mathrm{mg} / \mathrm{mL})\end{array}$ \\
\hline DSI-MAE & DPPH $\bullet$ & $\mathrm{Y}=0.69176+0.17516 \times$ & 0.35606 \\
& & $\ln (\mathrm{x}-0.01754)$ & \\
& ABTS $^{+} \bullet$ & $\mathrm{Y}=0.64654+0.15307 \times$ & 0.41477 \\
& & $\ln (\mathrm{x}-0.02532)$ & \\
Direct & DPPH $\bullet$ & $\mathrm{Y}=0.50935+0.22418 \times$ & \\
MAE & & $\ln (\mathrm{x}+0.09967)$ & 0.86490 \\
& ABTS $^{+}$ & $\mathrm{Y}=0.42032+0.17489 \times$ & \\
& & $\ln (\mathrm{x}+0.09326)$ & 1.49116 \\
\hline
\end{tabular}

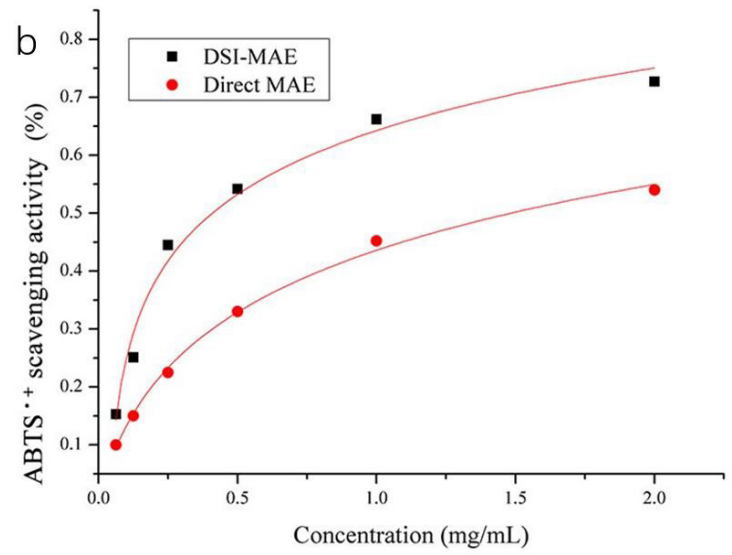

Figure 4. Antioxidant activities of extracts by steam spray pretreatment or direct MAE (Optimal microwave extraction conditions) under different concentrations of extract. a: Scavenging effects on DPPH free radical; b: scavenging effects on ABTS+ $\operatorname{radical}(n=3)$.

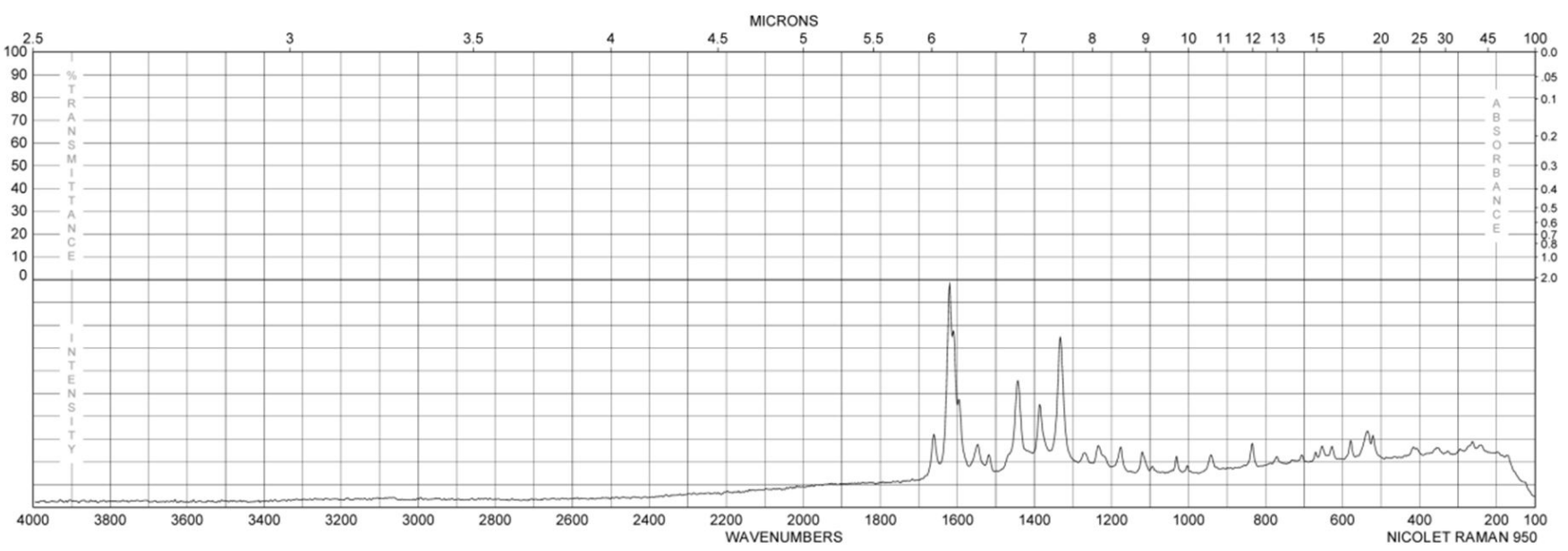

Figure 5. IR analysis of myricetin extracted from $\mathrm{H}$. dulcis. IR spectra of myricetin indicate the presence of hydroxyl $\left(3422 \mathrm{~cm}^{-1}\right)$, carbonyl $\left(1663 \mathrm{~cm}^{-1}\right)$, and aromatic groups $\left(1603,1514 \mathrm{~cm}^{-1}\right)$. 


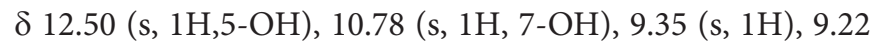
$(\mathrm{s}, 2 \mathrm{H}), 8.81(\mathrm{~s}, 1 \mathrm{H}), 7.24(\mathrm{~s}, 2 \mathrm{H}), 6.37(\mathrm{~s}, 1 \mathrm{H})$, and $6.18(\mathrm{~s}, 1 \mathrm{H})$. The one hydroxyl proton at $\delta 12.50(\mathrm{~s}, 1 \mathrm{H})$ of the A ring, and the presence of two protons at $6.37(\mathrm{~s}, 1 \mathrm{H})$, and $6.18(\mathrm{~s}, 1 \mathrm{H})$ were observed. The signal at $\delta 7.24(\mathrm{~s}, 2 \mathrm{H})$ for the flavonoid $\mathrm{B}$ ring indicates two symmetric protons. Compared with published ${ }^{1} \mathrm{H}$-NMR spectral data, the chemical structure was determined as myricetin (Tian et al., 2004).

\section{Conclusions}

The effects of various parameters, including steam injection time, methanol extraction concentration, and ratio of solvent to the material, and extraction temperature on the total flavonoids yield from $H$. dulcis were determined in this study. The results showed that the DSI pretreatment was more effective than that without the pretreatment based on the yield of total flavonoids. Moreover, the antioxidant activity of flavonoid extracts and recovery yield of total flavonoids obtained by DSI pretreatment was higher than that by direct MAE. Thus, the present study shows that the DSI pretreatment enhances the efficiency of MAE, and $H$. dulcis is a potential source of total flavonoids or other antioxidant agents for pharmaceutical applications.

\section{References}

Albuquerque, B. R., Prieto, M. A., Vazquez, J. A., Barreiro, M. F., Barros, L., \& Ferreira, I. C. F. R. (2018). Recovery of bioactive compounds from Arbutus unedo L. fruits: comparative optimization study of maceration/microwave/ultrasound extraction techniques. Food Research International, 109, 455-471. http://dx.doi.org/10.1016/j. foodres.2018.04.061. PMid:29803472.

Cao, J., Xia, X., Dai, X., Xiao, J., Wang, Q., Andrae-Marobela, K., \& Okatch, H. (2013). Flavonoids profiles, antioxidant, acetylcholinesterase inhibition activities of extract from Dryoathyrium boryanum (Willd.) Ching. Food and Chemical Toxicology, 55, 121-128. https://doi. org/10.1016/j.fct.2012.12.051.

Chan, C. H., Yusoff, R., Ngoh, G. C., \& Kung, F. W. (2011). Microwaveassisted extractions of active ingredients from plants. Journal of Chromatography. A, 1218(37), 6213-6225. http://dx.doi.org/10.1016/j. chroma.2011.07.040. PMid:21820119.

Chhikara, N., Kaur, R., Jaglan, S., Sharma, P., Gat, Y., \& Panghal, A. (2018). Bioactive compounds and pharmacological and food applications of Syzygium cumini - a review. Food \& Function, 9(12), 6096-6115. http://dx.doi.org/10.1039/C8FO00654G. PMid:30379170.

Elkhori, S., Paré, J. R. J., Bélanger, J. M. R., \& Pérez, E. (2007). The microwave-assisted process (MAP): extraction and determination of fat from cocoa powder and cocoa nibs. Journal of Food Engineering, 79(3), 1110-1114. http://dx.doi.org/10.1016/j.jfoodeng.2006.01.089.

Gasemloo, S., Khosravi, M., Sohrabi, M. R., Dastmalchi, S., \& Gharbani, P. (2019). Response surface methodology (RSM) modeling to improve removal of $\mathrm{Cr}(\mathrm{VI})$ ions from tannery wastewater using sulfated carboxymethyl cellulose nanofilter. Journal of Cleaner Production, 208, 736-742. http://dx.doi.org/10.1016/j.jclepro.2018.10.177.

Gómez, A. V., Tadini, C. C., Biswas, A., Buttrum, M., Kim, S., Boddu, V. M., \& Cheng, H. N. (2019). Microwave-assisted extraction of soluble sugars from banana puree with natural deep eutectic solvents (NADES). LWT, 107, 79-88. http://dx.doi.org/10.1016/j. lwt.2019.02.052.
Hemwimon, S., Pavasant, P., \& Shotipruk, A. (2007). Microwave-assisted extraction of antioxidative anthraquinones from roots of Morinda citrifolia. Separation and Purification Technology, 54(1), 44-50. http:// dx.doi.org/10.1016/j.seppur.2006.08.014.

Hyun, T. K., Eom, S. H., Yu, C. Y., \& Roitsch, T. (2010). Hovenia dulcis-an Asian traditional herb. Planta Medica, 76(10), 943-949. http://dx.doi.org/10.1055/s-0030-1249776. PMid:20379955.

Leão, D. P., Botelho, B. G., Oliveira, L. S., \& Franca, A. S. (2018). Potential of pequi (Caryocar brasiliense Camb.) peels as sources of highly esterified pectins obtained by microwave assisted extraction. $L W T$, 87, 575-580. http://dx.doi.org/10.1016/j.lwt.2017.09.037.

Lee, H. J., Gu, B. J., Ganjyal, G., \& Ryu, D. (2019). Reduction of ochratoxin A in direct steam injected oat-based infant cereals with baking soda. Food Control, 96, 441-444. http://dx.doi.org/10.1016/j. foodcont.2018.10.001.

Lewis, M., \& Heppel, N. (2001). Continuous thermal processing of foods. Pasteurization and UHT sterilization. International Journal of Food Microbiology, 67(1), 165-168. http://dx.doi.org/10.1016/ S0168-1605(01)00426-3.

Mandal, V., \& Mandal, S. C. (2010). Design and performance evaluation of a microwave based low carbon yielding extraction technique for naturally occurring bioactive triterpenoid: oleanolic acid. Biochemical Engineering Journal, 50(1-2), 63-70. http://dx.doi.org/10.1016/j. bej.2010.03.005.

Meng, Y., Su, A., Yuan, S., Zhao, H., Tan, S., Hu, C., Deng, H., \& Guo, Y. (2016). Evaluation of total flavonoids, myricetin, and quercetin from Hovenia dulcis Thunb. as inhibitors of $\alpha$-amylase and $\alpha$-glucosidase. Plant Foods for Human Nutrition (Dordrecht, Netherlands), 71(4), 1-6. http://dx.doi.org/10.1007/s11130-016-0581-2. PMid:27787697.

Ross, J. A., \& Kasum, C. M. (2002). Dietary flavonoids: bioavailability, metabolic effects, and safety. Annual Review of Nutrition, 22(1), 19-34. http://dx.doi.org/10.1146/annurev.nutr.22.111401.144957. PMid:12055336.

Siler, B., Zivkovic, S., Banjanac, T., Cvetkovic, J., Nestorovic Zivkovic, J., Ciric, A., Sokovic, M., \& Misic, D. (2014). Centauries as underestimated food additives: antioxidant and antimicrobial potential. Food Chemistry, 147, 367-376. http://doi.org/10.1016/j. foodchem.2013.10.007.

Tanongkankit, Y., Sablani, S. S., Chiewchan, N., \& Devahastin, S. (2013). Microwave-assisted extraction of sulforaphane from white cabbages: effects of extraction condition, solvent and sample pretreatment. Journal of Food Engineering, 117(1), 151-157. http://dx.doi.org/10.1016/j.jfoodeng.2013.02.011.

Tian, Y., Wu, J., \& Zhang, S. (2004). Flavonoids from leaves of Heritiera littoralis D. Journal of Chinese Pharmaceutical Sciences, 13, 214-216.

Wang, T., Li, H., Wang, H., \& Yuan, W. (2018). Research progress on ingredients function of Hovenia dulcis and its processing and utilization. Food and Nutrition in China, 24(10), 20-25.

Xiao, W., Han, L., \& Shi, B. (2008). Microwave-assisted extraction of flavonoids from Radix Astragali. Separation and Purification Technology, 62(3), 614-618. http://dx.doi.org/10.1016/j.seppur.2008.03.025.

Xu, Q., Shen, Y., Wang, H., Zhang, N., Xu, S., \& Zhang, L. (2013). Application of response surface methodology to optimise extraction of flavonoids from fructus sophorae. Food Chemistry, 138(4), 2122-2129. http://dx.doi.org/10.1016/j.foodchem.2012.11.099. PMid:23497866.

Xu, S. Y., Liu, J. P., Huang, X., Du, L. P., Shi, F. L., Dong, R., Huang, X. T., Zheng, K., Liu, Y., \& Cheong, K. L. (2018). Ultrasonic-microwave assisted extraction, characterization and biological activity of pectin from jackfruit peel. $L W T$, 90, 577-582. http://dx.doi.org/10.1016/j. lwt.2018.01.007. 